\title{
Discerning the optic nerve and retinochoroidal pathology using B-scan ultrasound in cases with anterior segment opacity
}

\author{
Jayanand Urkude, Rashmi Singh, Amar Pujari, Manthan Hasmukhbhai Chaniyara
}

Department of Ophthalmology, Dr Rajendra Prasad Centre for Ophthalmic Sciences, All India Institutes of Medical Sciences, New Delhi, India

Correspondence to Dr Amar Pujari,

dramarpujari@gmail.com

Accepted 28 July 2017

\section{DESCRIPTION}

Case 1: A posterior segment B-scan ultrasonography in a patient with typical iris coloboma and total cataract, showed well-defined excavated area in the inferior part just below the optic disc (red arrow) with the absence of retinochoroidal layer, suggestive of fundal coloboma (yellow arrow) (figure 1A). Involvement of macula and types of fundal coloboma can be ascertained quite fairly based on ultrasonography which might provide a clue or prediction about postoperative visual gain or visual prognosis. ${ }^{1}$

Case 2: Axial section ultrasonography in a 6-year-old child with total corneal opacity revealed a well-defined area of posterior excavation (yellow arrow) over the optic nerve head (red arrow) along with thinned out inferior neuroretinal rim (purple arrow) suggestive of optic disc coloboma (figure 1B). An entity like glaucomatous optic nerve cupping may be confused with optic disc coloboma but the simple hint of knowing thinned out inferior margin of optic nerve head in later case can give a clue to the diagnosis. Most of the time, these cases have syndromic association because of the same initial ultrasound assessment followed by relevant imaging and genetic evaluation is necessary. ${ }^{2}$

Case 3: Similarly, posterior segment scan in a patient with high myopia (axial length $=39 \mathrm{~mm}$ )
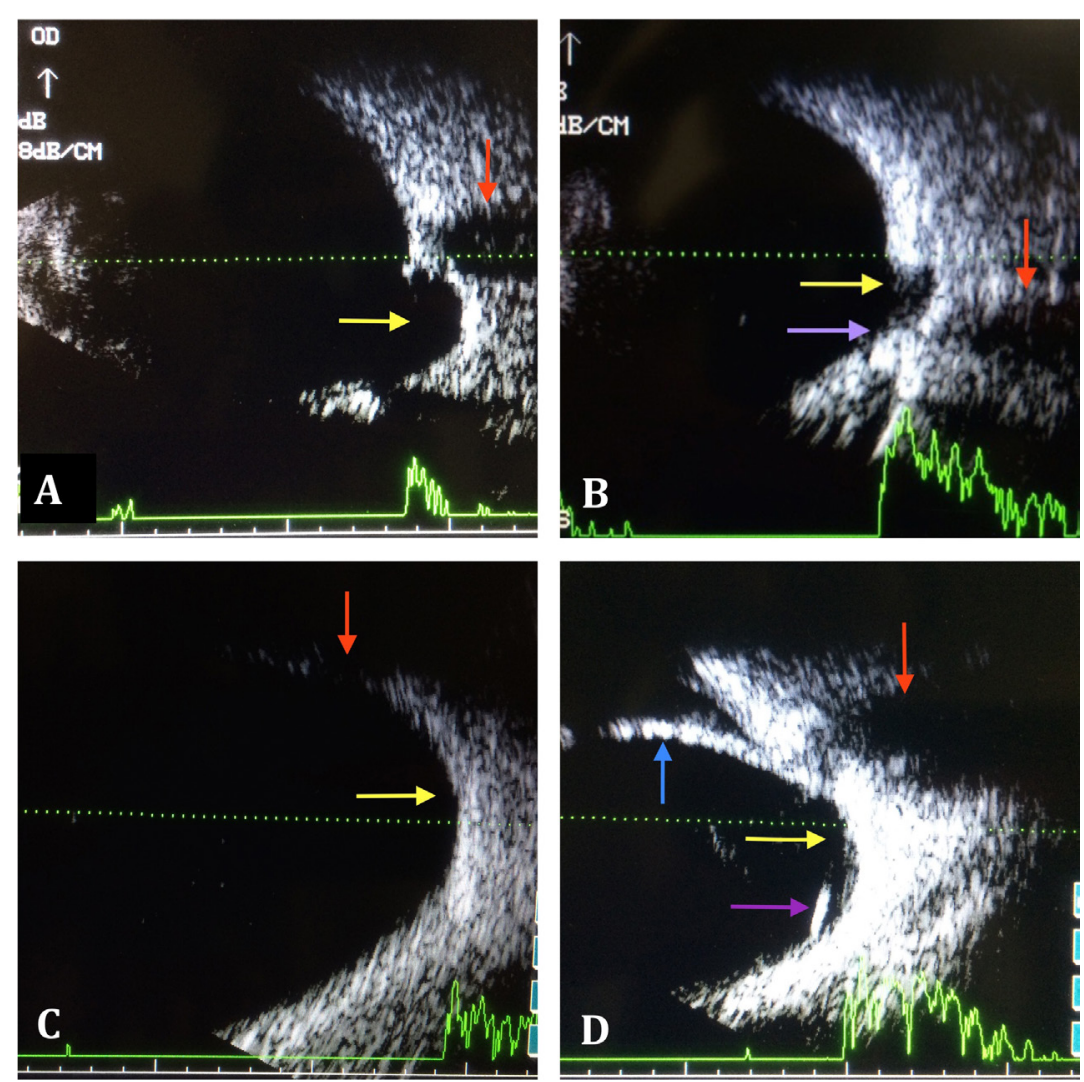

To cite: Urkude J, Singh $R$, Pujari A, et al. BMJ Case Rep Published Online First: [please include Day Month Year]. doi:10.1136/bcr-2017221549
Figure 1 (A) Axial scan depicting a well-defined posterior ocular coat excavation below the optic nerve head (red arrow) is suggestive of fundal coloboma (yellow arrow). (B) Axial scan showing a well-defined excavated area over the optic nerve head (red arrow) suggests an optic disc coloboma (yellow arrow) along with thinned out inferior neuroretinal rim (purple arrow). (C) Axial scan revealed an uniform diffuse posterior bowing of the entire ocular coat temporal to optic nerve head (red arrow) is suggestive of posterior staphyloma (yellow arrow). (D) Axial scan showing a high amplitude membranous echo (blue arrow) extending from the superior optic disc (red arrow) until the ora serrata persisting until low gain suggests retinal detachment in a case of fundal coloboma (yellow arrow). Purple arrow depicting the intercalary membrane. 
with total cataract revealed posterior bowing of the scleral coat along with thinning of chorioretinal layers at posterior pole (yellow arrow) and around the disc (red arrow) suggestive of posterior staphyloma (figure 1C). Pathological myopia is a common entity in clinical practice; diagnosing it in cases with corneal or lenticular opacities has its own importance, which can help in better explaining visual prognosis to the patients preoperatively.

Case 4: A posterior segment ultrasound in a 6-month-old child with a total cataractous lens, showed a well-defined area of excavation (yellow arrow) below the optic nerve head along with a high amplitude membranous echo extending from the superior part of the excavated area until the ora serrata suggestive of fundal coloboma with retinal detachment (blue arrow) (figure 1D). Intercalary membrane can be seen over the area of fundal coloboma (purple arrow). Knowing the preoperative status of the retina in detail and explaining postoperative visual outcome to the patient in such cases is of utmost important.

Diagnosing the optic nerve and retinochoroidal pathology is made simple by the various screening tools, which are available in present-day practice. Investigations such as indirect

\section{Learning points}

- Diagnosing posterior ocular coat abnormality is of paramount importance for ascertaining the definitive diagnosis and visual prognosis.

- Fundal coloboma with or without retinal detachment, posterior staphyloma and others need critical analysis before undertaking any visual rehabilitation surgeries. ophthalmoscopy, optical coherence tomography, fundus imaging and indocyanine green angiography have a vital role in distinguishing various posterior segment pathologies; however, it necessitates clear media. Certain anterior segment diseases need thorough posterior segment evaluation, which includes corneal opacity, corneal decompensation, total cataract, hyphema and vitreous haemorrhage, because the visual prognosis in these cases is guarded and routine posterior imaging modalities will not work.

In such cases, B-scan ultrasound can be a screening tool specifically devised to overcome the aforementioned media opacities. Simple clues on the B-scan ultrasound can help to reach diagnosis such as posterior bowing of ocular coat (posterior staphyloma), excavation without posterior bowing of ocular coat (fundal coloboma), optic nerve head excavation with thinned out inferior neuroretinal rim (optic disc coloboma) and separately detached membrane away from excavated posterior ocular coats (fundal coloboma with retinal detachment).

Contributors JU, RS, AP and MHC have evaluated the critical role of ultrasonography in cases with anterior segment media opacity. All authors have evaluated the critical role of this report and wrote the article.

Competing interests None declared.

Patient consent Obtained.

Provenance and peer review Not commissioned; externally peer reviewed.

(c) BMJ Publishing Group Ltd (unless otherwise stated in the text of the article) 2017. All rights reserved. No commercial use is permitted unless otherwise expressly granted.

\section{REFERENCES}

1 Gopal L, Badrinath SS, Kumar KS, et al. Optic disc in fundus coloboma. Ophthalmology 1996;103:2120-7.

2 Golnik KC. Cavitary anomalies of the optic disc: neurologic significance. Curr Neurol Neurosci Rep 2008:8:409-13.

Copyright 2017 BMJ Publishing Group. All rights reserved. For permission to reuse any of this content visit

http://group.bmj.com/group/rights-licensing/permissions.

BMJ Case Report Fellows may re-use this article for personal use and teaching without any further permission.

Become a Fellow of BMJ Case Reports today and you can:

- Submit as many cases as you like

- Enjoy fast sympathetic peer review and rapid publication of accepted articles

- Access all the published articles

Re-use any of the published material for personal use and teaching without further permission

For information on Institutional Fellowships contact consortiasales@bmjgroup.com

Visit casereports.bmj.com for more articles like this and to become a Fellow 